\title{
Gliding patterns of Siberian flying squirrels in relation to forest structure
}

\author{
Kei K Suzuki ${ }^{(1-2)}$, \\ Hisashi Yanagawa ${ }^{(1)}$
}

\section{Introduction}

Gliding locomotion has evolved independently in several animal classes, including mammals, reptiles, amphibians and insects. In mammals, gliding ability can be traced back more than 160 million years (Meng et al. 2017), and may have been common in early mammals (Han et al. 2017). Current-

(1) Laboratory of Wildlife Ecology, Obihiro University of Agriculture and Veterinary Medicine, Inada-cho, Obihiro, Hokkaido 0808555 (Japan); (2) Current address: Seikai National Fisheries Research Institute, Japan Fisheries Research and Education Agency, 1551-8 Taira, Nagasaki, Nagasaki 851-2213 (Japan)

@ Kei K Suzuki (pteromysuzuki@affrc.go.jp)

Received: Sep 03, 2018 - Accepted: Dec 17, 2018

Citation: Suzuki KK, Yanagawa H (2019). Gliding patterns of Siberian flying squirrels in relation to forest structure. iForest 12: 114117. - doi: 10.3832/ifor2954-011 [online 2019-02-11]

Communicated by: Massimo Faccoli

It is widely accepted that the evolution of gliding ability is correlated with forest environments, but differences in gliding locomotion in relation to forest structure remains poorly elucidated in mammals. Although the cost of gliding locomotion decreases with increasing glide distance per unit vertical drop (glide ratio), gliding mammals often use costly low-ratio glides and seldom exploit maximum-ratio glides. In this study, we evaluated our hypothesis that low-ratio glides are related to forest structure by measuring glide distance, vertical drops and landing tree heights in Siberian flying squirrels (Pteromys volans), and we also recorded their behaviour in landing trees. Glide ratio decreased with increasing landing tree height. Squirrels landed on taller trees using low-ratio glides and tended to depart from them quickly without spending much time there, but used high-ratio glides to land on shorter trees for foraging or nesting. Thus, flying squirrels use two different gliding behaviours depending on their immediate objective, where inefficient low-ratio glides are used to move to higher trees for continued gliding. This approach might be necessary for efficiency and safety in subsequent glides, because taller trees facilitate long-distance glides and significantly decrease energy costs and landing impact. Therefore, the location of tall trees in forests and/or average canopy height might alter glide path routes. This study provides important evidence that forest structure affects gliding patterns and provides insight on how forest management could influence the gliding locomotion of Siberian flying squirrels.

Keywords: Behaviour, Forest Structure, Forest Management, Gliding, Locomotion, Mammal, Tree Height

day gliding mammals have a wide geographical distribution (Goldingay 2000) and are strongly dependent on forest environments. Although it is widely accepted that the evolution of gliding ability is correlated with forest environments (Dudley \& DeVries 1990, Heinicke et al. 2012), studies exploring how gliding locomotion dependent on forest structure differs among mammals remain limited.

Gliding distance is determined by vertical drop. Although the cost of gliding decreases with increasing glide distance per vertical drop (glide ratio), gliding mammals frequently use costly low-ratio glides and seldom use more cost-effective glide ratios (Ando \& Shiraishi 1993, Krishna et al. 2016). However, the reason why gliding mammals frequently perform inefficient glides remains unclear. Several previous studies have demonstrated linear relationships between glide distance and vertical drop. This correlation has a relatively wide dispersion (Goldingay \& Taylor 2009, Stafford et al. 2002), which is manifested in variations in glide ratio. The large statistical residual indicates that glide distance may be determined by both vertical drop and other factors. Identifying the factors causing this dispersion could help clarify the purpose of costly low-ratio gliding.

Forest structure, including comparative tree height, might be an important factor contributing to this dispersion. Interestingly, there is an asymptotic negative correlation between glide distance and landing impact (Byrnes et al. 2008). Although this relationship seems counterintuitive, it could be attributed to the insufficient deboost of short distance glides. In addition, the energy costs associated with gliding decrease asymptotically with increasing glide distance (Flaherty et al. 2008). Therefore, long-distance glides are important in terms of decreasing landing impact (Byrnes et al. 2008) and maximizing efficiency. However, not all trees are tall enough to allow long distance glides, and gliding mammals may need to move to tall trees in order to facilitate these movements. Gliding mammals select a suitable landing point before launching (Caple et al. 1983). Therefore, we hypothesize that flying squirrels use initially low-ratio glides to move to adjacent tall trees to facilitate subsequent longer distance glides. If this hypothesis is correct, then both vertical drop and landing tree height determine glide distance, whereby landing tree height should influence the intercept and/or slope of the linear correlation between glide distance and vertical drop. In addition, when flying squirrels use a low-ratio glide to move to tall trees, they often take off again quickly 
Tab. 1 - Gliding parameters of Siberian flying squirrels (Pteromys volans). The mean values were previously reported by Suzuki et al. (2012). (SD): standard deviation.

\begin{tabular}{lrrrr}
\hline Parameter & Mean & SD & Min & Max \\
\hline Glide distance $(\mathrm{m})$ & 23.7 & 16.3 & 5.0 & 52.8 \\
Vertical drop $(\mathrm{m})$ & 12.0 & 6.9 & 2.0 & 25.8 \\
Glide ratio & 2.0 & 0.5 & 0.7 & 2.5 \\
Landing tree height $(\mathrm{m})$ & 19.4 & 4.4 & 11.5 & 26.5 \\
\hline
\end{tabular}

Tab. 2 - Linear mixed model selection based on the Akaike's information criterion (AIC). GD, VD, and TH are glide distance, vertical drop, and landing tree height, respectively. VD:TH is the interaction between these two variables. All models included a random intercept (nesting site ID).

\begin{tabular}{lcc}
\hline Model structure & AIC & $\Delta$ AIC \\
\hline GD $\sim$ VD + TH & 227.22 & - \\
GD $\sim$ VD & 229.81 & 2.59 \\
GD $\sim$ VD + TH + VD:TH & 233.11 & 5.89 \\
GD $\sim$ TH & 292.23 & 65.01 \\
\hline
\end{tabular}

from the tall tree. In this study, we tested our hypotheses by: (1) analysing the effects of both vertical drop and landing tree height on glide distance, and (2) recording flying squirrel behaviour in the trees on which they land.

\section{Methods}

Study area and gliding observations

We observed the gliding behaviour of Siberian flying squirrels (Pteromys volans L.) in urban forests with good visibility and flat ground (approximately 20 ha; $42^{\circ} 51^{\prime}$ $42^{\circ} 53^{\prime} \mathrm{N}, 143^{\circ} 09^{\prime}-143^{\circ} 11^{\prime} \mathrm{E}$ ) on Hokkaido Island, Japan. The forests consisted of conifers (29\%), including Japanese larch (Larix kaempferi [Lamb.] Carr.), and broadleaf trees (71\%), including Japanese emperor oak (Quercus dentata Thunb.). The mean height of the trees in this area was $15.3 \pm$ $5.6 \mathrm{~m}$ (SD). Observations were made almost daily from April to June 2010. As the area is dominated by deciduous trees, there was generally poor visibility in the canopy after late May, which hampered observations. Details of the study area are provided by Suzuki et al. (2012).

We located 17 nests (14 tree cavities and three nest boxes) of free-ranging Siberian flying squirrels and observed their gliding behaviour. The number of gliding observations per nest ranged from one to five (mean: $2.06 \pm 1.43$ ). Each glide was ob-

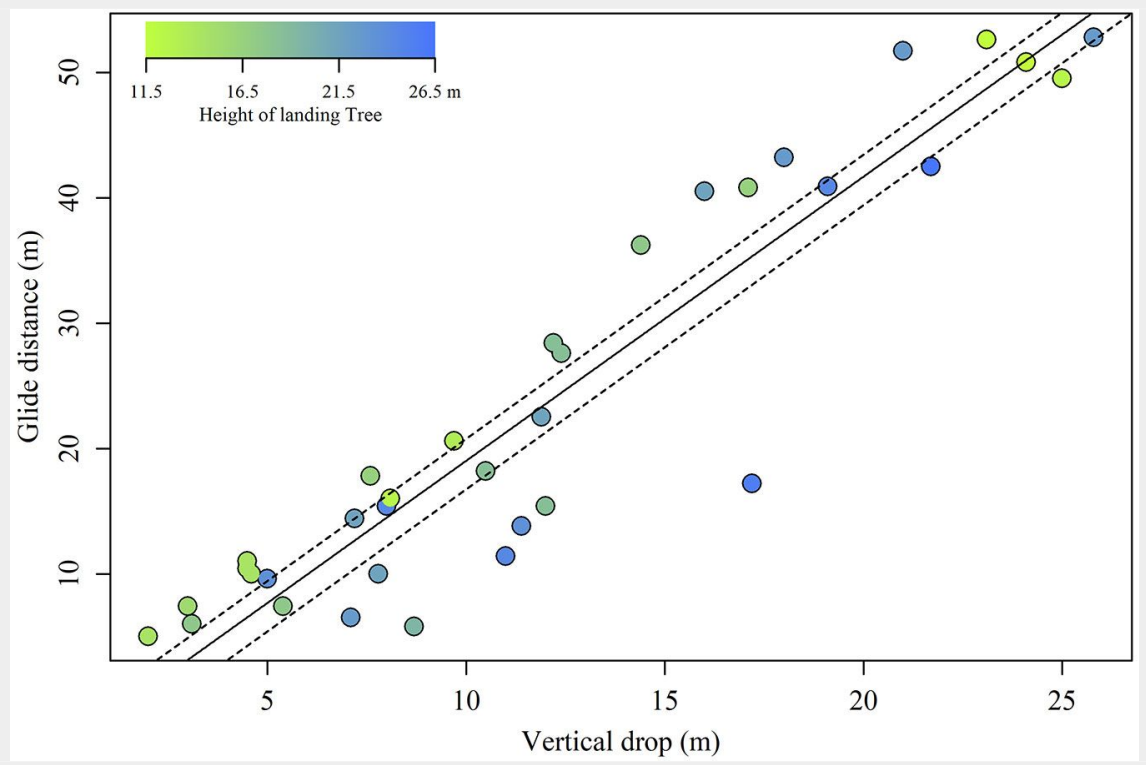

Fig. 1 - Glide distance as a function of vertical drop. Plot colour indicates landing tree height. Solid line: regression predicted using a linear mixed model. Upper and lower dashed lines: regressions assuming $25 \%(15.8 \mathrm{~m})$ and $75 \%(23.2 \mathrm{~m})$ of landing tree height, respectively. served by two or three researchers, with one determining launch point and the remaining one or two determining landing point. Horizontal glide distance, launch height, landing height and landing tree height were measured using a Nikon Laser 550AS (Nikon Corp., Tokyo, Japan). Vertical drop was calculated as the difference between the launch height and the landing height (Suzuki et al. 2012). In addition, we recorded behaviour in landing trees for approximately $10 \mathrm{~min}$ after landing. No animals were trapped, and none were observed using artificial lighting to minimise disturbance caused by researchers.

\section{Statistical analysis}

We evaluated the effect of the vertical drop and landing tree height on glide distance. Because glide distance, as the dependent variable, followed a normal distribution (Kolmogorov-Smirnov test: $\mathrm{D}=$ $0.20, P=0.11$ ), we evaluated it using a linear mixed model (LMM). Vertical drop, landing tree height and their interaction were used as independent variables. Nest ID was added as a random effect to avoid pseudoreplication and unclear effects for the same individual. The best model was selected using the Akaike Information Criterion (AIC). Each influence of the fixed effects in the best model was evaluated us ing an $F$ test. These analyses were run using the "Imer" function of the "Ime4" package in R and the "anova" function in R ver. 3.2.4 (R Core Team 2016).

\section{Results}

\section{Gliding locomotion}

During the course of the study, we observed 35 glides of Siberian flying squirrels (Tab. 1). Glide ratios varied from 0.7 to 2.5 . In approximately $50 \%$ of all glides, the ratios were $\leq 2.0$. Both vertical drop and landing tree height were ranked as best-fit models (Tab. 2), where vertical drop strongly affected glide distance (coefficient $=2.27 ; F=230.9 ; P<0.001$ ) with an evident linear correlation (Fig. 1), and landing tree height also influenced glide distance (coefficient $=-0.55 ; F=6.4 ; P=0.015$ ). However, the interaction between these variables was not included in this best-fit model (Tab. 2). Accordingly, although landing tree height determined the intercept, it did not affect the slope of the linear correlation between vertical drop and glide distance. Specifically, the intercept of the linear regression was -1.9 when a $25 \%(15.8 \mathrm{~m})$ landing tree height was assumed, but was -5.9 when a $75 \%(23.2 \mathrm{~m})$ landing tree height was assumed (Fig. 1). Therefore, the glide ratios were consistently lower when Siberian flying squirrels landed on taller trees compared to shorter ones.

Specifically, the intercept of the linear regression was -1.9 when a $25 \%(15.8 \mathrm{~m})$ landing tree height was assumed. In contrast, it was -5.9 when a $75 \%(23.2 \mathrm{~m})$ landing tree height was assumed (Fig. 1). Therefore, the 
glide ratios were consistently lower when the Siberian flying squirrels landed on taller trees than when they landed on smaller trees.

\section{Behaviours on landing trees}

Behaviours on landing trees were observed after 11 glides (Tab. 3). For the remaining 24 glides, the squirrels hid in the canopy area and were lost from view. In five glides, squirrels launched again from landing trees; the height of these trees ranged from 22.1 to $26.2 \mathrm{~m}$ (mean: $23.8 \pm$ 1.6), and they were thus taller than the mean height of all landing trees $(19.4 \mathrm{~m} \pm$ 4.4 - Tab. 1, Fig. 2). Glides to these trees had lower glide ratios (0.9-1.9) than the mean glide ratio of $2.0 \pm 0.5$ (Tab. 1, Fig. 2). Thus, Siberian flying squirrels used low-ratio glides to move to tall trees for their subsequent glides.

In the five instances in which feeding behaviour was observed after landing, landing tree height ranged from 11.5 to $23.4 \mathrm{~m}$ (mean: $12.0 \pm 0.9)$. These glides tended to have higher glide ratios (2.0-2.5) compared to the mean glide ratio (Tab. 1, Fig. 2). In one case where a squirrel hid in a tree cavity after landing, the landing tree height and glide ratio were $17.5 \mathrm{~m}$ and 2.5 , respectively. The ratio of this glide was the second highest of all 35 glides recorded (Tab. 1, Fig. 2). The landing tree height was approximately equivalent to the mean landing tree height. In addition, this cavity was used as nest site, because there was abundant nesting material derived from tree bark in the cavity. Therefore, Siberian flying squirrels appear to use high-ratio glides to move to trees used for foraging or nesting.

\section{Discussion}

Although several studies have focused on gliding locomotion in mammals, reptiles, amphibians and insects (Bahlman et al. 2013, Dudley et al. 2007, Goldingay 2014, Socha 2002), the role of the costly low-ratio glide has been previously overlooked. Our study aimed to assess the function of low-ratio glides. Glide ratios were consistently lower for glide to taller trees (Fig. 1). Although we could not measure the distance of subsequent glides from these landing trees (because we could not view subsequent landing points), landing trees for the first glides had sufficient height to facilitate long-distance glides (Suzuki et al. 2012). Therefore, we suggest that low-ratio glides serve as a means of travelling to a tall tree, which then facilitates long-distance glides, contributing to safe and efficient movement in gliding mammals (Byrnes et al. 2008, Flaherty et al. 2008).

In comparison, Siberian flying squirrels that used the high-ratio glide used the landing tree as a feeding or hiding (in a nest) site. Our study also showed that there is a wide range of the landing tree heights in high-ratio glides (Fig. 2). Thus, squirrels use high-ratio glides when moving towards a tree in which they intend to feed

Tab. 3 - Behaviours of Siberian flying squirrels (Pteromys volans) in landing trees.

\begin{tabular}{lcc}
\hline Behaviour & Glide ratio & Landing tree height $(\mathbf{m})$ \\
\hline Gliding & 0.92 & 22.5 \\
Gliding & 1.00 & 26.2 \\
Gliding & 1.21 & 23.8 \\
Gliding & 1.89 & 22.1 \\
Gliding & 1.92 & 24.2 \\
\hline Feeding & 1.98 & 13.1 \\
Feeding & 2.05 & 23.4 \\
Feeding & 2.11 & 11.5 \\
Feeding & 2.28 & 11.5 \\
Feeding & 2.46 & 23.2 \\
\hline Hiding in cavity & 2.51 & 17.5 \\
\hline
\end{tabular}

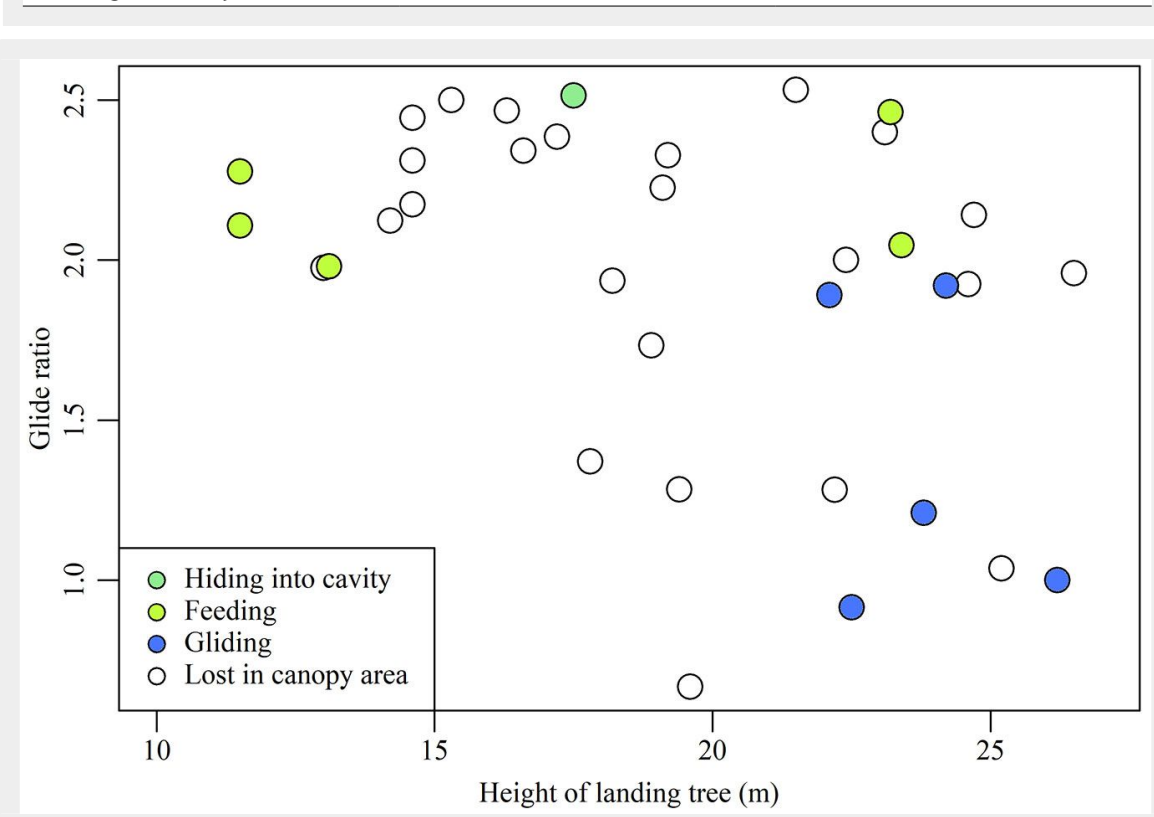

Fig. 2 - Correlation between glide ratio and landing tree height. Plot colour indicates behaviours in landing trees.

or nest, rather than those from which they undertake subsequent glides (Fig. 2). Nest site selection in Siberian flying squirrels is not correlated with tree height (Suzuki et al. 2013). Accordingly, when gliding to reach target trees, squirrels save energy and time by using high-ratio glides. Thus, squirrels deploy two different gliding strategies, depending on their intention: low-ratio glides to facilitate subsequent travel, and high-ratio glides to reach a specific destination. As such, the location of tall trees in forests and/or average canopy height might determine the routes of glide paths.

A similarly wide range of glide ratios has also been observed in other gliding mammals. For example, glide ratios range from 0.6 to 3.5 in Japanese giant flying squirrels (Ando \& Shiraishi 1993) and 1.1 to 2.5 in the mahogany glider (Petaurus gracilis) and the sugar glider (Petaurus breviceps - Jackson 1999). These, and other species, seldom display maximum glide ratios (Ando \& Shiraishi 1993, Krishna et al. 2016). Tree thickness also influences landing tree choice in giant flying squirrels (Krishna et al. 2016). Overall, these findings strongly imply that forest structure influences the gliding locomotion of gliding mammals.

\section{Conclusions}

Stafford et al. (2002) proposed that gliding behaviour is more diverse than previously believed and that environmental geometry might contribute towards determining glide paths. The present study provides important evidence that forest structure can have a prominent effect on determining the route of glide paths. These results could be applied to devise forest management approaches that take into account the gliding locomotion of Siberian flying squirrels.

We found that the low-ratio glide is common in Siberian flying squirrels in this study area. This phenomenon might be caused by low-tree height in the study area (mean height: $15.3 \mathrm{~m}$ - see methods section). Thus, Siberian flying squirrels might need to land on tall trees to ensure efficiency and safety in subsequent glides. Con- 
versely, in forests with taller trees, the rate of low-ratio glides might be lower, facilitating long glides. Thus, it is important to clarify the relationship between gliding locomotion and forest structure in future studies by comparing the rates of low-ratio glides among forests with diverse tree heights.

\section{Acknowledgements}

We thank K. Ono, T. Kubo, M. Minoshima, and D. Yoshimatsu at Obihiro University of Agriculture and Veterinary Medicine for providing support with the field observations. We thank Editage (http://www.edit age.jp) for English language editing. We acknowledge the invaluable comments of the reviewers on earlier versions of this manuscript.

\section{References}

Ando M, Shiraishi S (1993). Gliding flight in the Japanese giant flying squirrel Petaurista leucogenys. Journal of Mammalogical Society of Japan 18: 19-32. [online] URL: http://www.j stage.jst.go.jp/article/jmammsocjapan/18/1/18_1 19/_article/-char/ja/

Bahlman JW, Swarts SM, Riskin DK, Breuer KS (2013). Glide performance and aerodynamics of non-equilibrium glides in northern flying squirrels (Glaucomys sabrinus). Journal of the Royal Society Interface 10 (80): 20120794-20120794. doi: 10.1098/rsif.2012.0794

Byrnes G, Lim T-NL, Spence AJ (2008). Take-off and landing kinetics of a free-ranging gliding mammal, the Malayan colugo (Galeopterus variegatus). Proceedings of the Royal Society $B$ 275: 1007-1013. - doi: 10.1098/rspb.2007.1684 Caple G, Balda R, Willis WR (1983). The physics of leaping animals and the evolution of preflight. American Naturalist 121: 455-467. - doi: 10.1086/ 284076

Dudley R, Byrnes G, Yanovial SP, Borrell B, Brown RM, McGuire JA (2007). Gliding and the functional origins of flight: biomechanical novelty or necessity? Annual Review of Ecology, Evolution and Systematics 38: 179-201. - doi: 10.1146/annurev.ecolsys.37.091305.110014

Dudley R, DeVries P (1990). Tropical rain forest structure and the geographical distribution of gliding vertebrates. Biotropica 22: 432-434. doi: $10.2307 / 2388564$

Flaherty EA, Scheibe JS, Goldigay R (2008). Locomotor performance in the squirrel glider, $\mathrm{Pe}$ taurus norfolcensis, and the sugar glider, Petaurus breviceps. Australian Mammalogy 30: 25-35. - doi: 10.1071/AM08003

Goldingay RL (2000). Gliding mammals of the world: diversity and ecological requirements. In: "Biology of Gliding Mammals" (Goldingay RL, Scheibe JS eds). Filander Press, Fürth, Germany, pp. 5-40.

Goldingay RL (2014). Gliding performance in the yellow-bellied glider in low-canopy forest. Australian Mammalogy 36: 254-258. - doi: 10.1071/ AM14006

Goldingay RL, Taylor BD (2009). Gliding performance and its relevance to gap crossing by the squirrel glider (Petaurus norfolcensis). Australian Journal of Zoology 57: 99-104. - doi: 10.1071/ ZO09003

Han G, Mao F, Bi S, Wang Y, Meng J (2017). A Jurassic gliding euharamiyidan mammal with an ear of five auditory bones. Nature 551: 451456. - doi: $10.1038 /$ nature 24483

Heinicke MP, Greenbaum E, Jackman TR, Bauer AM (2012). Evolution of gliding in Southeast Asian geckos and other vertebrates is tempo- rally congruent with dipterocarp forest development. Biology Letters 8: 994-997. - doi: 10.1098/rsbl.2012.0648

Jackson SM (1999). Glide angle in the genus Petaurus and a review of gliding in mammals. Mammal Review 30: 9-30. - doi: 10.1046/j.13652907.2000.00056.x

Krishna MC, Kumar A, Tripathi OP (2016). Gliding performance of the red giant gliding squirrel Petaurista petaurista in the tropical rainforest of Indian eastern Himalaya. Wildlife Biology 22: 7-12. - doi: 10.2981/wlb.00120

Meng QJ, Grossnickle DM, Liu D, Zhang Y-G, Neander Al, Ji Q, Luo Z-X (2017). New gliding mammaliaforms from the Jurassic. Nature 548: 291296. - doi: $10.1038 /$ nature23476

R Core Team (2016). R: a language and environment for statistical computing. R Foundation for Statistical Computing, Vienna, Austria. [online] URL: http://www.r-project.org/

Socha JJ (2002). Kinematics: gliding flight in the paradise tree snake. Nature 418: 603-604. - doi: 10.1038/418603a

Stafford BJ, Thorington RW, Kawamichi T (2002). Gliding behavior of Japanese giant flying squirrels (Petaurista leucogenys). Journal of Mammalogy 83: 553-562. - doi: 10.1644/15451542(2002)083<0553:GBOJGF>2.0.CO;2

Suzuki K, Asari Y, Yanagawa H (2012). Gliding locomotion of Siberian flying squirrels in lowcanopy forests: the role of energy-inefficient short-distance glides. Acta Theriologica 57: 131135. - doi: 10.1007/s13364-011-0060-y

Suzuki K, Sagawa M, Yanagawa H (2013). Nest cavity selection by the Siberian flying squirrel Pteromys volans. Hystrix 24: 187-189. - doi: 10.44 04/hystrix-24.2-8975 